\title{
Total Hydroperoxide and Biological Antioxidant Potentials in a Neonatal Sepsis Model
}

\author{
HIROKI KAKITA, MOHAMED H. HUSSEIN, GHADA A. DAOUD, TAKENORI KATO, HIROKI MURAI, \\ TAKAHIRO SUGIURA, KEISUKE MIZUNO, YASUMASA YAMADA, TETSUYA ITO, SUMIO FUKUDA, INEKO KATO, \\ SATOSHI SUZUKI, AND HAJIME TOGARI
}

Department of Pediatrics [H.K., M.H.H., G.A.D., T.K., H.M., T.S., K.M., Y.Y., T.I., S.F., I.K., S.S., H.T.], Neonatology and Congenital Disorders, Nagoya City University Graduate School of Medical Sciences, Nagoya 467-8601, Japan; Neonatal Intensive Care Unit [M.H.H.], Pediatric Hospital, Cairo University, Cairo 11559, Egypt; Department of Maternal and Child Health [M.H.H., G.A.D.], VACSERA, Giza 22311, Egypt

\begin{abstract}
Oxidant/antioxidant imbalance plays an important role in septic shock. The present study examined changes in circulating oxidative components in a neonatal sepsis model. Subjects were 14 newborn mixed-strain piglets randomly divided into two groups: a cecal ligation and perforation (CLP) model $(n=7)$ and sham $(n=7)$. Blood samples for total hydroperoxide $(\mathrm{TH})$, biological antioxidant potential (BAP), tumor necrosis factor (TNF) $\alpha$, interleukin (IL)-6, and IL-10 were collected pre-CLP and at 1, 3, and $6 \mathrm{~h}$ post-CLP. TH and BAP levels at $1 \mathrm{~h}$ post-CLP were significantly higher in the CLP group than in the sham group. In the CLP group, TH decreased gradually and reached baseline levels by $6 \mathrm{~h}$ post-CLP, while BAP remained elevated. Linear correlations were identified between serum TH and BAP at $1 \mathrm{~h}$ post-CLP, serum TH and TNF- $\alpha$ at $1 \mathrm{~h}$ post-CLP, and BAP and IL- 6 at $6 \mathrm{~h}$ post-CLP. Changes in and correlations between circulating oxidative and inflammatory state components in a neonatal sepsis model were clarified. This is the first study to reveal that the presence of oxidant/antioxidant imbalance in sepsis and septic shock changes during the disease course. (Pediatr Res 60: 675-679, 2006)
\end{abstract}

$T_{i}$ The incidence, morbidity, and mortality of sepsis occurring in neonatal intensive care units has remained relatively high, despite progress in the management of very ill neonates (1). During serious Gram-negative bacterial infection, many of the local and systemic pathophysiological phenomena produced by lipopolysaccharide (LPS) in the exposed host result from the ability of LPS to activate host inflammatory cells (2), including monocytes, macrophages, and polymorphonuclear leukocytes. However, LPS provokes excessive production and secretion of proinflammatory cytokines, a process that plays an important role in the development of sepsis, septic shock, and multiple organ failure $(3,4)$. Various cytokines produced by monocytes and macrophages, such as IL- 6 and TNF- $\alpha$ are known to be activated by infection in the early neonatal period $(5,6)$.

Several reports have suggested that oxidant/antioxidant imbalance plays a significant role in the pathogenesis of neonatal sepsis and associated complications $(7,8)$. The main effect of

Received March 6, 2006; accepted August 8, 2006.

Correspondence: Hiroki Kakita, M.D., Department of Pediatrics, Neonatology and Congenital Disorders, Nagoya City University Graduate School of Medical Sciences, 1 Kawasumi, Mizuho-cho, Mizuho-ku, Nagoya 467-8601, Japan; e-mail: hkaki@med.nagoyacu.ac.jp

DOI: 10.1203/01.pdr.0000245911.79943.8a reactive oxygen species (ROS) is found on the cell membrane, lipids, and nucleic acids (9).

Total hydroperoxide (TH) levels represent a measure of overall oxidative damage, indicating the intermediate oxidative forms of lipids, peptides, and amino acids. Furthermore, the $\mathrm{TH}$ value was shown to be very useful to individuate subjects at risk of oxidative stress (10). Determination of $\mathrm{TH}$ therefore provides information on some of the fundamental mechanisms of oxidative stress involved in the critically ill newborn (10). Conversely, biological antioxidant potentials (BAP) is used to represent overall antioxidative activity. The serum BAP provides a reliable measurement of the power of the antioxidant barrier to oxidation, which is directly involved due to the implicating decreasing oxidant potential against the attack of ROS in physiological and biological conditions (11). Newborns, particularly preterm infants, are at high risk of oxidative stress and are extremely susceptible to oxidative damage by ROS (12). This is because newborns have less protection against oxidation (13). Compared with healthy adults, newborns display lower levels of plasma antioxidants such as vitamin $\mathrm{E}$ and betacarotene, lower levels of plasma metal-binding proteins such as ceruloplasmin and transferrin, and reduced activity of erythrocyte superoxide dismutase (14).

Despite the great efforts expended, the causes of oxidant/ antioxidant imbalance in sepsis remain unclear. We have designed a modified neonatal sepsis CLP model that yields a blood culture of Gram-negative anaerobes and Gram-positive bacteria (15). The present study aimed to clarify, for the first time, the changes in circulating oxidative components and relationships to different cytokines in a neonatal sepsis model.

\section{MATERIALS AND METHODS}

Animal preparation. Experiments were performed in adherence with the National Institutes of Health guidelines on the use of experimental animals, and the protocol was approved by the Ethics Committee of Nagoya City University Graduate School of Medical Sciences. Subjects were14 newborn mixed-strain piglets obtained at $3 \mathrm{~d}$ old from a local farmer, divided into two groups: a CLP group $(n=7)$ and a sham group $(n=7)$. Piglets were maintained with their

Abbreviations: BAP, biological antioxidant potentials; CLP, cecal ligation and perforation; LPS, lipopolysaccharide; ROS, reactive oxygen species; TH, total hydroperoxide 
mothers and were transported on the day of the procedure. Mean [ \pm standard error of the mean (SEM)] weight was $1715 \pm 47.6 \mathrm{~g}$ in the CLP group and $1762 \pm$ $159 \mathrm{~g}$ in the sham group. Piglets were premedicated with intramuscular injection of ketamine chloride $(10 \mathrm{mg} / \mathrm{kg})$, after which anesthesia was induced using pentobarbital sodium $(5 \mathrm{mg} / \mathrm{kg} / \mathrm{h})$ in $5 \%$ glucose solution via a peripheral line at a rate of $5 \mathrm{~mL} / \mathrm{kg} / \mathrm{h}$ throughout the study to avoid hypovolemia. All surgical procedures were performed under sterile conditions. Each piglet underwent a tracheotomy and was intubated with an endotracheal tube (4.0-mm internal diameter) and ventilated using an IV-100 infant ventilator (Sechrist Industries, Anaheim, CA). Inspiration/expiration pressures were initially set at $14 / 4 \mathrm{~cm} \mathrm{H}_{2} \mathrm{O}$, with an inspiration time of $0.5 \mathrm{~s}$ using room air. Pressures were then adjusted to maintain $\mathrm{PaCO}_{2}$ at $30-50 \mathrm{~mm} \mathrm{Hg}$. A cut-down procedure was used to insert a $3 \mathrm{~F}$ polyvinyl catheter into the left femoral artery for blood sampling and measuring the systemic blood pressure (SBP). The SBP was measured with a neonatal monitor (model 78801 B: Hewett Packard, Andover, MA). Body temperature was maintained using a thermal pad to prevent hypothermia and was monitored by a rectal probe.

Modified CLP was performed on 3-d-old piglets in the CLP group as previously described (15). Briefly, a paramedian incision approximately $4 \mathrm{~cm}$ long was made, sufficient to expose the cecum and terminal ileum. The ileocecal artery was identified and ligated near the cecum, resulting in devascularization of the distal end of the cecum. A 1-cm incision was made on the antimesenteric side. The cecum was gently milked to extrude feces into the peritoneal cavity. The abdominal incision was then closed in two layers. In the sham group, the cecum was exposed for $2 \mathrm{~min}$, and then the abdomen was closed in two layers. Animals surviving to $6 \mathrm{~h}$ post-CLP were killed with a lethal dose of phenobarbital sodium. The clinical parameters of the CLP group, including SBP, arterial blood gas (ABG), and body temperature showed dramatic changes rapidly after $3 \mathrm{~h}$ postCLP, and some CLP piglets died soon after $6 \mathrm{~h}$ post-CLP (15). Therefore, $6 \mathrm{~h}$ was chosen for termination of the experiment.

Experimental protocol. In both sham and CLP groups, blood samples were aseptically collected from the femoral arterial catheter to determine plasma LPS, ABG, serum TH, BAP, TNF- $\alpha$, IL-6, and IL-10 at pre-CLP and 1, 3, and $6 \mathrm{~h}$ post-CLP. All samples were placed into heparinized pyrogen-free sterilized tubes. Serum samples were obtained by centrifugation at $3000 \mathrm{rpm}$ for 10 min, followed by immediate storage at $-30^{\circ} \mathrm{C}$ until the time of analysis.

Measurements. ABG was analyzed with standard analyzer (model 1248; CIBA Corning, Medfield, MA). Plasma LPS levels were measured using a commercial Limulus amebocyte lysate assay kit (Toray Industries, Tokyo, Japan). Serum TNF- $\alpha$, IL-6, and IL-10 were measured using immunoassay kits specific for porcine TNF- $\alpha$, IL-6, and IL-10 (GT, Minneapolis, MN), respectively.

TH production was measured using a d-ROMs Kit (Diacron srl, Parma, Italy), as previously described (10). In the presence of iron (which is released from the proteins by an acidic buffer), free radicals are able to generate alkoxyl $\left(\mathrm{RO}^{\bullet}\right)$ and peroxyl $\left(\mathrm{ROO}^{\bullet}\right)$ radicals, according to Fenton's reaction. Such radicals, in turn, are able to oxidize an alkyl-substituted aromatic amine (A- $\mathrm{NH}_{2}$, dissolved in chromogenic mixture), thus transforming them into a pink-colored derivative $\left(\left[\mathrm{A}-\mathrm{NH}_{2}{ }^{\bullet}\right]+\right)$ according to the reactions:

1A. $\mathrm{ROOH}+\mathrm{Fe}^{2+} \rightarrow \mathrm{RO}^{\bullet}+\mathrm{Fe}^{3+}+\mathrm{OH}^{-}$(for alkoxyl radicals) 1B. $\mathrm{RO}^{\bullet}+\mathrm{A}-\mathrm{NH}_{2} \rightarrow \mathrm{RO}^{-}+\left[\mathrm{A}-\mathrm{NH}_{2}{ }^{\bullet}\right]^{+}$(pink)

2A. $\mathrm{ROOH}+\mathrm{Fe}^{2+} \rightarrow \mathrm{ROO}^{\bullet}+\mathrm{Fe}^{2+}+\mathrm{H}^{+}$(for peroxyl radicals) 2B. $\mathrm{ROO}^{\bullet}+\mathrm{A}-\mathrm{NH}_{2} \rightarrow \mathrm{ROO}^{-}+\left[\mathrm{A}-\mathrm{NH}_{2}^{\bullet}\right]^{+}$(pink).

Finally, this colored derivative was photometrically quantified. Intensity of developed color is directly proportional to the concentration of TH. The d-ROMs test was performed using the following standard working conditions: wavelength 505 or $546 \mathrm{~nm}$, optical path $1 \mathrm{~cm}$, and temperature $37^{\circ} \mathrm{C}$. Results were expressed in conventional arbitrary units, called Carr units, equal to a concentration of $0.08 \mathrm{mg} / \mathrm{dL}$ of hydrogen peroxide.

BAP was measured using a commercial assay kit (Diacron srl). The BAP test is based on the ability of a colored solution, containing a source of ferric $\left(\mathrm{Fe}^{3+}\right)$ ions adequately bound to a special chromogenic substrate, to decolor when $\mathrm{Fe}^{3+}$ ions are reduced to ferrous ions $\left(\mathrm{Fe}^{2+}\right)$, as it occurs by adding a reducing/antioxidant system, i.e. a blood serum sample. In the BAP test, the small amount of blood serum $(10 \mu \mathrm{L})$ to be tested is dissolved in a colored solution, which has been previously obtained by mixing a source of ferric ions (ferric chloride, $\mathrm{FeCl}_{3}$ ) with a special chromogenic substrate (thiocyanate derivative). After a short incubation of $5 \mathrm{~min}$ at $37^{\circ} \mathrm{C}$, such solutions decolorized and the intensity of this chromatic change is considered directly proportional to the ability of serum during the incubation to reduce ferric ions to ferrous ions. By photometrically assessing the intensity of decolonization, the amount of reduced ferric ions can be adequately evaluated, allowing effective measurement of reducing ability or antioxidant potential of tested blood serum (11). Based on the ability of a colored solution containing a source of ferric ions to adequately bind to a special chromogenic substrate and decolor when $\mathrm{Fe}^{3+}$ ions are reduced to ferrous ions $\left(\mathrm{Fe}^{2+}\right)$ :
Step 1: $\mathrm{FeCl}_{3}+\mathrm{AT}$ (uncolored) $\rightarrow \mathrm{FeCl}_{3}-\mathrm{AT}$ (colored)

Step 2: $\mathrm{FeCl}_{3}-\mathrm{AT}$ (colored) $+\mathrm{BP}\left(\mathrm{e}^{-}\right) \rightarrow \mathrm{FeCl}_{2}+\mathrm{AT}$ (decolored) $+\mathrm{BP}$

where AT (uncolored) is a thiocyanate derivative (uncolored) $\mathrm{FeCl}_{3}-\mathrm{AT}$ (colored) is a colored complex of ferric chloride with thiocyanate derivative; $\mathrm{BP}\left(\mathrm{e}^{-}\right)$is a molecule of the substance measured to show antioxidant activity against ferric ions; and $\mathrm{BP}$ is the oxidized form of $\mathrm{BP}\left(\mathrm{e}^{-}\right)$. The $\mathrm{BAP}$ test was performed on the following standard working conditions: wavelength 505 (range, 500-510) nm, optical path $1 \mathrm{~cm}$, and temperature $37^{\circ} \mathrm{C}$.

Statistical analysis. The means of the two groups (intergroups) at the same time points were compared using analysis of variance (ANOVA). If data were not normally distributed, the Mann-Whitney test was used. Comparing means of the observations in the same group (intragroup) at different time was done using ANOVA for repeated measures, followed by the Tukey-Kramer post hoc test. Coefficients of correlation were tested using Pearson two-tailed correlation coefficients. If data were nonparametric, the Spearman two-tailed test was used. Data are reported as mean \pm SEM. Probability values of $p<$ 0.05 were considered statistically significant. All data analyses were performed using SPSS commercially available statistical analysis software (Chicago, IL)

\section{RESULTS}

Animal profile. All piglets were $3 \mathrm{~d}$ old, and no significant difference in weight was seen between the CLP and sham groups. No deaths occurred in either group within $6 \mathrm{~h}$.

Body temperature, mean SBP, and ABG. We observed a gradual increase in body temperature in both groups, and it became significantly higher at 3 and $6 \mathrm{~h}$ post-CLP than pre-CLP (Table 1). The body temperature in the CLP group was significant higher than in the sham group at $6 \mathrm{~h}$ post-CLP (Table 1).

The $\mathrm{pH}$ value decreased significantly at $6 \mathrm{~h}$ post-CLP in the CLP group compared with the sham group (Table 1), whereas $\mathrm{pH}$ values remained essentially unchanged in the sham group throughout the experiments. The $\mathrm{pH}$ value at $6 \mathrm{~h}$ post-CLP was significant lower than pre-CLP and 1 and $3 \mathrm{~h}$ post-CLP in the CLP group (Table 1).

The mean SBP showed no differences between the two groups until $3 \mathrm{~h}$ post-CLP. The mean SBP in the CLP group decreased steadily and became significant lower than in the sham group at $6 \mathrm{~h}$ post-CLP, whereas mean SBP values remained essentially unchanged in the sham group during the experiments (Table 1). The mean SBP at $6 \mathrm{~h}$ post-CLP was significant lower than pre-CLP and 1 and $3 \mathrm{~h}$ post-CLP in the CLP group (Table 1).

Plasma LPS. Plasma LPS levels showed no differences between sham and CLP groups pre-CLP, but were significantly higher in the CLP group at 1 and $6 \mathrm{~h}$ post-CLP (Table 2). The mean plasma LPS level was higher in the CLP group at $3 \mathrm{~h}$ post-CLP, but this difference did not reach significance. The plasma LPS levels at 1,3, and $6 \mathrm{~h}$ post-CLP were higher than at pre-CLP only in the CLP group (Table 2).

Serum TH and BAP. Serum levels of TH and BAP showed no differences between the sham and CLP groups pre-CLP, but were higher in the CLP group at $1 \mathrm{~h}$ post-CLP (TH: $298.4 \pm 24.1$ Carr units versus $225.8 \pm 14.9$ Carr units; BAP: $2598.1 \pm 82.6$ $\mu \mathrm{mol} / \mathrm{L}$ versus $2239.3 \pm 104.6 \mu \mathrm{mol} / \mathrm{L}$, respectively; $p<0.05$ ) (Fig. 1). Mean serum TH in the CLP group continued to decrease after $1 \mathrm{~h}$ post-CLP, and serum levels in the CLP group resembled those in the sham group at $6 \mathrm{~h}$ post-CLP (Fig. $1 \mathrm{~A}$ ). Mean BAP levels remained higher in the CLP group than in the sham group after $1 \mathrm{~h}$ post-CLP, and these differences were also significantly higher at $6 \mathrm{~h}$ post-CLP $(2556.83 \pm 105.9 \mu \mathrm{mol} / \mathrm{L}$ versus $2039.7 \pm 130.6 \mu \mathrm{mol} / \mathrm{L}$, respectively, $p<0.05$ ), but at $3 \mathrm{~h}$ post-CLP (Fig. 1B). 
Table 1. Body temperature, $p H$, and mean SBP change in the CLP and sham groups

\begin{tabular}{|c|c|c|c|c|c|}
\hline Group & Pre-CLP & $1 \mathrm{~h}$ post-CLP & $3 \mathrm{~h}$ post-CLP & $6 \mathrm{~h}$ post-CLP & $p$ value* \\
\hline \multicolumn{6}{|c|}{ Body temperature $\left({ }^{\circ} \mathrm{C}\right)$} \\
\hline CLP & $37.0 \pm 0.5$ & $39.2 \pm 0.5 \dagger$ & $39.9 \pm 0.2 \dagger$ & $41.1 \pm 0.6 \dagger t$ & $<0.001$ \\
\hline Sham & $37.5 \pm 0.3$ & $38.5 \pm 0.4$ & $39.5 \pm 0.5 \dagger$ & $39.0 \pm 0.3 \dagger$ & $<0.001$ \\
\hline \multicolumn{6}{|l|}{$\mathrm{pH}$} \\
\hline CLP & $7.41 \pm 0.02$ & $7.40 \pm 0.03$ & $7.38 \pm 0.05$ & $7.21 \pm 0.02 \dagger \ddagger \S$ & $<0.001$ \\
\hline Sham & $7.45 \pm 0.03$ & $7.43 \pm 0.05$ & $7.41 \pm 0.03$ & $7.43 \pm 0.05$ & NS \\
\hline CLP & $71.3 \pm 5.3$ & $67.2 \pm 5.7$ & $71.3 \pm 4.4$ & $33.0 \pm 5.1 \dagger \dagger \S$ & $<0.001$ \\
\hline Sham & $68.6 \pm 3.0$ & $68.5 \pm 4.7$ & $62.2 \pm 5.2$ & $60.9 \pm 4.3$ & NS \\
\hline$p$ value $\|$ & NS & NS & NS & $<0.01$ & \\
\hline
\end{tabular}

Data are expressed as mean \pm SEM.

* ANOVA for repeated measures.

$\dagger \ddagger \S p<0.05$ compared with $\dagger$ pre-CLP, $\ddagger 1 \mathrm{~h}$ post-CLP, $\S 3 \mathrm{~h}$ post-CLP, and followed by the Tukey-Kramer post hoc tests.

|| Mann-Whitney test, CLP versus sham at that time point.

NS, not significant.

Table 2. Plasma LPS in the CLP and sham groups

\begin{tabular}{lccccc}
\hline & Pre-CLP & $1 \mathrm{~h}$ post-CLP & $3 \mathrm{~h}$ post-CLP & $6 \mathrm{~h}$ post-CLP & $p$ value* \\
\hline CLP $(\mathrm{ng} / \mathrm{ml})$ & $0.14 \pm 0.06$ & $3.48 \pm 1.74 \dagger$ & $1.2 \pm 0.37 \dagger$ & $1.21 \pm 1.34 \dagger$ \\
Sham $(\mathrm{ng} / \mathrm{ml})$ & $0.05 \pm 0.04$ & $0.64 \pm 0.81$ & $0.33 \pm 0.1$ & $0.147 \pm 0.153$ & $\mathrm{NS}$ \\
$p$ value $\dagger$ & NS & $<0.05$ & NS & $<0.05$ & \\
\hline
\end{tabular}

Data are expressed as mean \pm SEM.

*ANOVA for repeated measures.

$\dagger p<0.05$ compared with pre-CLP and follow-up by the Tukey-Kramer post hoc tests.

$\ddagger$ Mann-Whitney test, CLP versus sham at that time point.

NS, not significant.

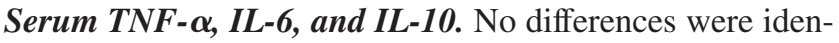
tified between the two groups in serum TNF- $\alpha$ and IL- 6 levels pre-CLP. TNF- $\alpha$ levels in the CLP group were significantly higher than in the sham group at $1 \mathrm{~h}$ post-CLP $(212.8 \pm 91.4$ $\mathrm{pg} / \mathrm{mL}$ versus $15.3 \pm 5.6 \mathrm{pg} / \mathrm{mL}$, respectively $(p<0.001)$, and remained significantly higher at 3 and $6 \mathrm{~h}$ post-CLP $(3 \mathrm{~h}$ post-CLP: $238.9 \pm 46.4 \mathrm{pg} / \mathrm{mL}$ versus $40.1 \pm 32 \mathrm{pg} / \mathrm{mL}, p<$ $0.005 ; 6$ h post-CLP: $218.4 \pm 41.2 \mathrm{pg} / \mathrm{mL}$ versus $24.2 \pm 8.2$ pg/mL, $p<0.001$, respectively) (Fig. $2 A$ ).

IL-6 levels in the CLP group continued to increase throughout the study after CLP and were significantly higher than in the sham group at 3 and $6 \mathrm{~h}$ post-CLP ( $3 \mathrm{~h}$ post-CLP: $389.2 \pm$ $104.7 \mathrm{pg} / \mathrm{mL}$ versus $160.8 \pm 94.3 \mathrm{pg} / \mathrm{mL}, p<0.05 ; 6 \mathrm{~h}$ post-CLP: $1213.3 \pm 4467.2 \mathrm{pg} / \mathrm{mL}$ versus $199.8 \pm 137.1$
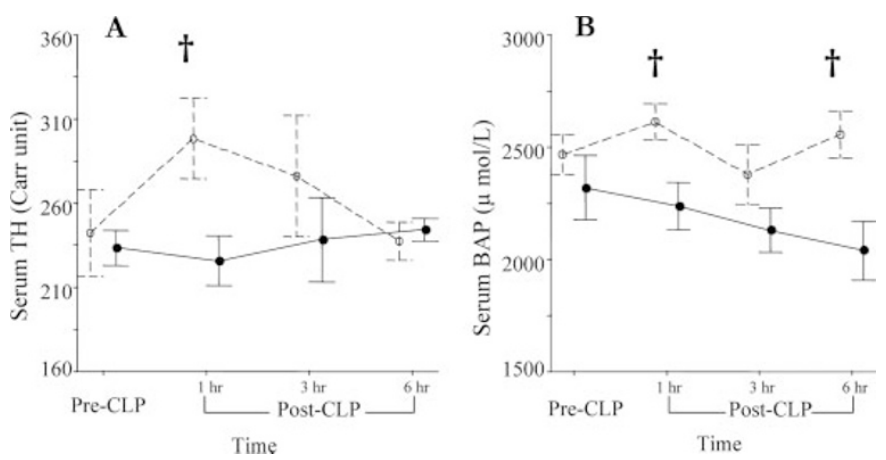

Figure 1. Serial serum levels of TH $(A)$ and BAP $(B)$ in the CLP group $(n=7)$ and sham group $(n=7)$. Open circles, CLP group; closed circles, sham group. The error bar represents the SEM. $\dagger p<0.05$ using the Mann-Whitney test. $\mathrm{pg} / \mathrm{mL}, p<0.05$, respectively) (Fig. $2 B$ ). There was no significant difference detected in the IL-10 serum levels between the two groups throughout the experiments.

Correlations. Serum TH and BAP displayed a significant positive correlation at $1 \mathrm{~h}$ post-CLP $(r=0.6, n=14, p<$ 0.05) (Fig. 3), but not at 3 and $6 \mathrm{~h}$ post-CLP.

At $1 \mathrm{~h}$ post-CLP, a significant positive correlation was identified between serum TH and TNF- $\alpha(r=0.75, n=14, p<$ 0.005) (Fig. 4A), but not at 3 and $6 \mathrm{~h}$ post-CLP. At $6 \mathrm{~h}$ post-CLP, a significant positive correlation was identified between serum BAP and IL-6 ( $r=0.62, n=14, p<0.05$ ) (Fig. 4B), but not at 1 and $3 \mathrm{~h}$ post-CLP. The serum levels of IL-10 showed significant negative correlations with TNF- $\alpha(r=-0.601, n=14, p<$ $0.05)$, TH $(r=-0.742, n=14, p<0.01)$, and BAP $(r=-0.899, n=14, p<0.001)$ at $1 \mathrm{~h}$ post-CLP, but not at 3 and $6 \mathrm{~h}$ post-CLP. At $6 \mathrm{~h}$ post-CLP, there was a significant negative correlation between IL-6 and IL-10 ( $r=-0.832, n=$ $14, p=0.003$ ), but not at 1 and $3 \mathrm{~h}$ post-CLP.

\section{DISCUSSION}

Under physiologic conditions, a homeostatic balance exists between the formation of reactive oxidizing/oxygen species and removal by endogenous antioxidant scavenging compounds (16). Oxidative stress occurs when this balance is disrupted by excessive production of ROS or inadequate antioxidant defenses, and both may occur in sepsis (17). The close relationship between free radicals and sepsis has been described in previous studies $(18,19)$, but the influences of ROS and antioxidants in sepsis patients remain unclear, particularly in neonates. Some studies 

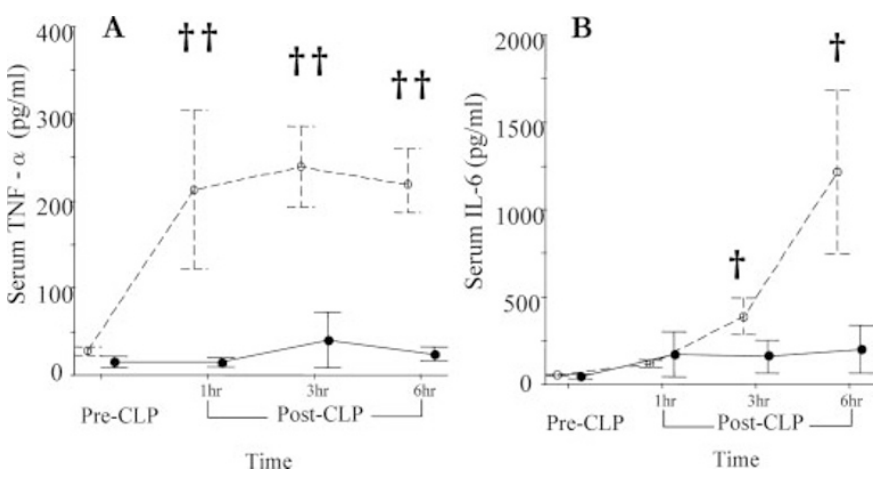

Figure 2. Serial serum levels of TNF- $\alpha(A)$ and IL-6 (B) in the CLP group $(n$ $=7)$ and in the sham group $(n=7)$. Open circles, CLP group; closed circles, sham group. The error bar represents the SEM. $\dagger p<0.05, \dagger \dagger p<0.005$ using the Mann-Whitney test.

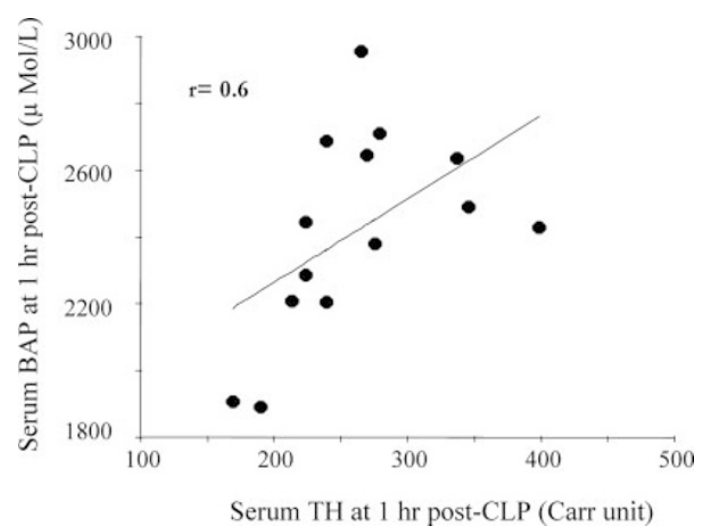

Figure 3. Correlation between serum $\mathrm{TH}$ and $\mathrm{BAP}$ at $1 \mathrm{~h}$ post-CLP $(r=0.6$, $n=14, p=0.02$ ). The coefficient of correlation was tested using the Spearman two-tailed test correlation coefficient.
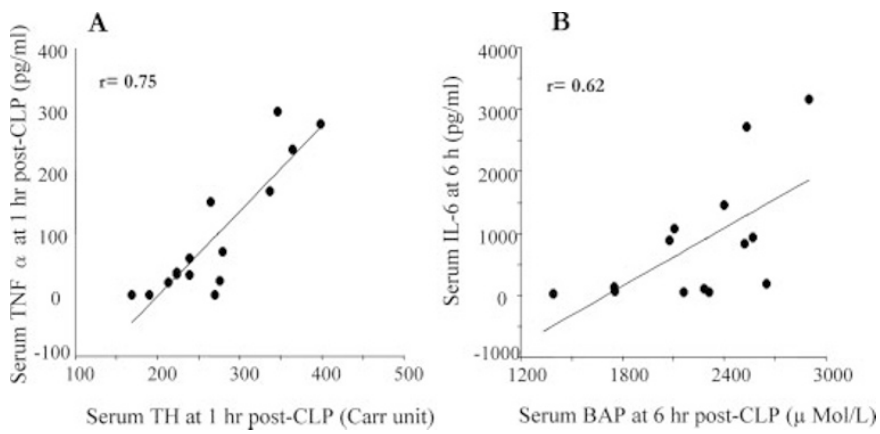

Figure 4. Correlation between serum TNF- $\alpha$ and TH at $1 \mathrm{~h}$ post-CLP $(r=$ $0.75, n=14, p=0.002)$ using the Pearson two-tailed correlation coefficient (A) and serum IL-6 and BAP at $6 \mathrm{~h}$ post-CLP $(r=0.62, n=14, p=0.03)$ using the Spearman two-tailed correlation coefficient $(B)$.

have measured oxidative parameters in sepsis (19-21), but few studies have examined neonates $(7,8)$.

The present work demonstrated associations between serum ROS, antioxidant potentials, and cytokines in a characterized neonatal sepsis model (15). Time changes were seen in the inflammatory state with simultaneous changes in the oxidative state. At $1 \mathrm{~h}$ post-CLP, TH and TNF- $\alpha$, the proinflammatory cytokine, predominated. At $6 \mathrm{~h}$ post-CLP, both antioxidants and IL-6, as both an anti- and proinflammatory cytokine $(22,23)$, were predominant.

For protection against the toxic effects of free radicals, enzymes have evolved that specifically scavenge superoxide anions, hydrogen peroxide and organic peroxides, and subsequently repair the damage in nucleic acids $(17,24)$. Primary antioxidants prevent oxygen radical formation either by removing free radical precursors or by inhibiting catalysis, such as glutathione peroxidase, superoxide dismutase, and catalase. Secondary antioxidants react with ROS that have already been formed to either remove or inhibit them, such as vitamins C and E. Endogenous antioxidants exist in a number of locations: intracellularly; on the cell membrane; and extracellularly $(17,24)$. Although several reports have described the behaviors of antioxidants in sepsis, the ways in which antioxidants cope with increased oxidant load during sepsis have not been widely studied $(7,19,20)$. Circulating antioxidants cannot be viewed as simple chemicals, and measurement of individual components is unlikely to yield a complete picture of the in vivo situation. Some investigators have demonstrated no changes in glutathione peroxidase concentration, whereas others have demonstrated increases in both concentrations of the enzymes superoxide dismutase, catalase, and glutathione peroxidase and total antioxidant capacity $(7,8,25)$. Our results support these latter reports, as serum BAP levels increased after $1 \mathrm{~h}$ post-CLP and remained elevated throughout the study in the CLP group, although the differences did not reach significance at $3 \mathrm{~h}$ post-CLP.

IL-6 is a pleiotropic cytokine with both pro- and antiinflammatory properties $(22,23)$. IL-6 displays multiple biologic activities, including proliferation of hemopoietic stem cells, potentiation of T-cell proliferative responses, and induction of hepatic acute-phase protein synthesis (26). Several reports have described the protective effects of IL-6 against $\mathrm{O}_{2}$ toxicity (27-29). The antioxidant effects of IL-6, however, remain unclear. Tsan et al. (30) showed that IL-6 markedly enhances TNF- $\alpha$ and IL-1-induced increases in Mn superoxide dismutase mRNA levels and $\mathrm{O}_{2}$ tolerance. In contrast, Ward et al. (28) suggested that the antioxidant effects of IL-6 are not associated with significant alternations in SOD activity, but are associated with the enhanced accumulation of the cell-death inhibitor Bcl-2. This might explain the correlation between IL- 6 and BAP at $6 \mathrm{~h}$ post-CLP in our study.

The rapid elevation of TH levels in our neonatal CLP model occurred earlier than in other studies $(20,21)$. Ritter et al. (21) reported that ROS showed a trend toward higher levels at 37-48 $\mathrm{h}$ after CLP, followed by a trend to decline at $49-60 \mathrm{~h}$ in adult rats. Victor and De la Fuente. (20) showed that levels of ROS in adult mice increased gradually and peaked $24 \mathrm{~h}$ after LPS injection. These differences could be due to the fact that our model was a neonatal sepsis model, not an adult model, and immune responses in neonates differ from those in adults exposed to infection (31). In addition, our model was of a more severe nature than used in other studies $(20,21)$. Furthermore, the rapid increase of TH in our study could have been provoked by early rapid elevation of TNF- $\alpha$. Sanlioglu et al. (32) suggested that activation of Rac1 (a GTP-binding protein), and subsequent production of ROS, constitute a major pathway involved in TNF- $\alpha$ secretion after LPS challenge in macrophages. In addition, proinflammatory agonists like LPS, TNF, and IL-1 promote the production of ROS (33). Both of these findings suggest that proinflammatory cytokines positively regulate ROS and vice 
versa. Our results might support such conditions in vivo. Some reports state that ROS induces antioxidants $(25,33)$. Oxidation by ROS causes dissociation of Keap1 from the nuclear factor erythroid-2-related factor 2 (Nrf2)-Keap1 complex, allowing free Nrf2 to migrate from the cellular cytoplasm to the nucleus (34). Nrf2 in the nucleus shares in the transcription factor complex that activates the transcription series of gene coding for phase 2 enzymes, which in turn up-regulates antioxidant synthesis (35). Our results support these reports in vivo and showed positive correlations between both serum TH and BAP at $1 \mathrm{~h}$ post-CLP and continuous elevation of BAP until $6 \mathrm{~h}$ post-CLP. IL-10 is an anti-inflammatory cytokine and a key physiologic negative regulator of macrophage activation. Activated macrophages produce various inflammatory mediators including TNF- $\alpha$ and nitric oxide, all of which are suppressed by IL-10 (36). This could explain the negative significant correlations of IL-10 with TNF- $\alpha$, TH, and $\mathrm{BAP}$ at $1 \mathrm{~h}$ post-CLP, and with IL- 6 at $6 \mathrm{~h}$ post-CLP, which was found in our study.

Several reports note ROS increases in patients suffering from severe sepsis $(14,25)$ and in animal models of sepsis $(19,21)$, compared with noncritical sepsis or controls, respectively. To the best of our knowledge, no previous reports have shown that ROS levels in sepsis can return to basal levels during the disease course. Our results, that TH levels in the CLP group resembled those in the sham group at $6 \mathrm{~h}$ post-CLP, indicate that ROS is not always high in sepsis. One possible reason for these results would be the counteracting effect caused by later increases in serum BAP, as indicated by the tendency toward a negative correlation to TH at $6 \mathrm{~h}$, although no significant relationship was found.

In sepsis, the oxidant/antioxidant imbalance concept suggests that high levels of oxidant and low levels of antioxidant are involved in poor outcomes $(4,37,38)$. Our results suggest that the involvement of oxidant/antioxidant imbalance in sepsis and septic shock depends on timing along the disease course.

Evaluating the oxidative state of a critically ill newborn to measure TH and BAP is an easily and quickly performed bedside technique using a small amount of blood $(60-70 \mu \mathrm{L})$ and is thus suitable for small newborns, especially the prematurely born.

In the pathophysiology and therapy of neonatal sepsis, consideration of these time changes and the balance of ROS and antioxidants with concomitant changes in inflammatory cytokines would appear crucial. This is the first report to find that oxidant/antioxidant imbalances, with high levels of oxidants and low levels of antioxidants, are not always present in sepsis and septic shock, and their involvement is time dependent along the disease course. In addition, measuring TH and BAP can provide a good marker of oxidative state in critically ill newborns.

\section{REFERENCES}

1. Parravicini E, van de Ven C, Anderson L, Cario MS 2002 Myeloid hematopoietic growth factors and their role in prevention and/or treatment of neonatal sepsis. Transfus Med Rev 16:11-24

2. Heumann D, Gallay P, Barras C, Zaech P, Ulevitch RJ, Tobias PS, Glauser MP, Baumgartner JD 1992 Control of lipopolysaccharide (LPS) binding and LPSinduced tumor necrosis factor secretion in human peripheral blood monocytes. J Immunol 148:3505-3512

3. Bone RC, Sprung CL, Sibbald WJ 1992 Definition for sepsis and organ failure. Crit Care Med 20:724-726

4. Wolkow PP 1998 Involvement and dual effects of nitric oxide in septic shock. Inflamm Res 47:152-166

5. Silveira RC, Procianoy RS 1999 Evaluation of interleukin-6, tumor necrosis factoralpha and interleukin-1beta for early diagnosis of neonatal sepsis. Acta Paediatr 88:647-650
6. Berner R, Welter P, Brandis M 2002 Cytokine expression of cord and adult blood mononuclear cells in response to Streptococcus agalactiae. Pediatr Res 51:304-309

7. Batra S, Seema Kumar R, Seema Kapoor AK, Ray G 2000 Alterations in antioxidant status during neonatal sepsis. Ann Trop Paediatr 20:27-33

8. Seema Kumar R, Mandal RN, Tandon A, Randhawa VS, Mehta G, Batra S, Ray GN, Kapoor AK 1999 Serum TNF-alpha free radical scavengers in neonatal septicemia. Indian J Pediatr 66:511-516

9. Oldham KM, Bowen PE 1998 Oxidative stress in critical care: is antioxidant supplementation beneficial? J Am Diet Assoc 98:1001-1008

10. Buonocore G, Perrone S, Longini M, Terzuoli L, Bracci R 2000 Total hydroperoxide and advanced oxidation proteins products in preterm hypoxic babies. Pediatr Res 47:221-224

11. Dohi K, Satoh K, Ohtaki H, Shioda S, Miyake Y, Shindo M, Aruga T 2005 Elevated plasma levels of bilirubin in patients with neurotrauma reflect its pathophysiological role in free radical scavenging. In Vivo 19:855-860

12. Saugstad OD 1996 Mechanisms of tissue injury by oxygen radicals: implications for neonatal disease. Acta Paediatr 85:1-4

13. Hara K, Yamashita S, Fujisawa A, Ishiwa S, Ogawa T, Yamamoto Y 1999 Oxidative stress in newborn infants with and without asphyxia as measured by plasma antioxidants and free fatty acids. Biochem Biophys Res Commun 257:244-248

14. Gitto E, Karbownik M, Reiter RJ, Tan DX, Cuzzocrea S, Chiurazzi P, Cordaro S, Corona G, Trimarchi G, Barberi I 2001 Effects of melatonin treatment in septic newborns. Pediatr Res 50:756-760

15. Kato T, Hussein MH, Sugiura T, Suzuki S, Fukuda S, Tanaka T, Kato I, Togari H 2004 Development and characterization of a novel porcine model of neonatal sepsis. Shock 21:329-335

16. Gutteridge JM, Mitchell J 1999 Redox imbalance in the critically ill. Br Med Bull 55:49-75

17. Victor VM, Rocha M, De la Fuente M 2004 Immune cells: free radicals and antioxidants in sepsis. Int Immunopharmacol 4:327-347

18. Macarthur H, Westfall TC, Riley DP, Misko TP, Salvemini D 2000 Inactivation of catecholamines by superoxide gives new insights on the pathogenesis of septic shock. Proc Natl Acad Sci U S A 97:9753-9758

19. Andrades M, Ritter C, Moreira JC, Dal-Pizzol F 2005 Oxidative parameters differences during non-lethal and lethal sepsis development. J Surg Res 125:68-72

20. Victor VM, De la Fuente M 2003 Immune cells redox state from mice with endotoxininduced oxidative stress. Involvement of NF-kappaB. Free Radic Res 37:19-27

21. Ritter C, Andrades M, Frota Junior ML Bonatto F, Pinho RA, Polydro M, Klamt F, Pinheiro CT, Menna-Barreto SS, Moreira JC, Dal-Pizzol F 2003 Oxidative parameters and mortality in sepsis induced by cecal ligation and perforation. Intensive Care Med 29:1782-1789

22. Nijsten MW, de Groot ER, ten Duis HJ Klasen HJ, Hack CE, Aarden LA 1987 Serum levels of interleukin-6 and acute phase responses. Lancet 2:921

23. Tilg H, Trehu E, Atkins MB, Dinarello CA, Mier JW 1994 Interleukin-6 (IL-6) as an anti-inflammatory cytokine: induction of circulating IL-1 receptor antagonist and soluble tumor necrosis factor receptor p55. Blood 83:113-118

24. Yu BP 1994 Cellular defenses against damage from reactive oxygen species. Physiol Rev 74:139-162

25. Pascual C, Karzai W, Meier-Hellmann A, Oberhoffer M, Horn A, Bredle D, Reinhart K 1998 Total plasma antioxidant capacity is not always decreased in sepsis. Crit Care Med 26:705-709

26. Yoshida Y, Maruyama M, Fujita T, Arai N, Hayashi R, Araya J, Matsui S, Yamashita N, Sugiyama E, Kobayashi M 1999 Reactive oxygen intermediates stimulate interleukin-6 production in human bronchial epithelial cells. Am J Physiol 276:L900-L908

27. Williams JG, Bernstein S, Prager M 1998 Effect of melatonin on activated macrophage TNF, IL-6, and reactive oxygen intermediates. Shock 9:406-411

28. Ward NS, Waxman AB, Homer RJ, Mantell LL, Einarsson O, Du Y, Elias JA 2000 Interleukin-6-induced protection in hypoxic acute lung injury. Am J Respir Cell Mol Biol 22:535-542

29. Waxman AB, Mahboubi K, Knickelbein RG, Mantell LL, Manzo N, Pober JS, Elias JA 2003 Interleukin-11 and interleukin-6 protect cultured human endothelial cells from H2O2-induced cell death. Am J Respir Cell Mol Biol 29:513-522

30. Tsan MF, White JE, Del Vecchio PJ, Shaffer JB 1992 IL-6 enhances TNF-alpha- and IL-1-induced increase of Mn superoxide dismutase mRNA and $\mathrm{O} 2$ tolerance. Am J Physiol 263:L22-L26

31. Kemp AS, Campbell DE 1996 The neonatal immune system. Semin Neonatol 1:67-75

32. Sanlioglu S, Williams CM, Samavati L, Butler NS, Wang G, McCray PB Jr., Ritchie TC, Hunninghake GW, Zandi E, Engelhardt JF 2001 Lipopolysaccharide induces Rac1dependent reactive oxygen species formation and coordinates tumor necrosis factor-alpha secretion through IKK regulation of NF-kappa B. J Biol Chem 276:30188-30198

33. Sozzani S, Bosisio D, Mantovani A, Ghezzi P 2005 Linking stress, oxidation and the chemokine system. Eur J Immunol 35:3095-3098

34. Dinkova-Kostova AT, Holtzclaw WD, Cole RN, Itoh K, Wakabayashi N, Katoh Y, Yamamoto M, Talalay P 2002 Direct evidence that sulfhydryl groups of Keap1 and sensors regulating induction of phase 2 enzymes that protect against carcinogens and oxidants. Proc Natl Acad Sci USA 99:11908-11913

35. Holtzclaw WD, Dinkova-Kostova AT, Talalay P 2004 Protection against electrophile and oxidative stress by induction of phase 2 genes: the quest for the elusive sensor that responds to inducers. Adv Enzyme Regul 44:335-367

36. Qasimi P, Ming-Lum A, Ghanipour A, Ong CJ, Cox ME, Ihle J, Cacalano N, Yoshimura A, Mui AL 2006 Divergent mechanisms utilized by SOCS3 to mediate interleukin-10 inhibition of tumor necrosis factor alpha and nitric oxide production by macrophages. J Biol Chem 281:6316-6324

37. Ogilvie AC, Groeneveld AB, Straub JP, Thijis LG 1991 Plasma lipid peroxides and antioxidants in human septic shock. Intensive Care Med 17:40-44

38. Goode HF, Cowley HC, Walker BE, Howdle PD, Webster NR 1995 Decreased antioxidant status and increased lipid peroxidation in patients with septic shock and secondary organ dysfunction. Crit Care Med 23:646-651 